\title{
ARTICLE
}

\section{Impact-induced shock and the formation of natural quasicrystals in the early solar system}

\author{
Lincoln S. Hollister ${ }^{1, \star}$, Luca Bindi ${ }^{2, \star}, N_{a n}$ Yao $^{3, \star}$, Gerald R. Poirier $^{3, \dagger}$, Christopher L. Andronicos $^{4}$, \\ Glenn J. MacPherson ${ }^{5}$, Chaney Lin ${ }^{6}$, Vadim V. Distler ${ }^{7}$, Michael P. Eddy ${ }^{8}$, Alexander Kostin 9 , \\ Valery Kryachko ${ }^{7}$, William M. Steinhardt ${ }^{10}$, Marina Yudovskaya ${ }^{7}$, John M. Eiler ${ }^{11}$, Yunbin Guan ${ }^{11}$, \\ Jamil J. Clarke ${ }^{12} \&$ Paul J. Steinhardt 6,13
}

The discovery of a natural quasicrystal, icosahedrite $\left(\mathrm{Al}_{63} \mathrm{Cu}_{24} \mathrm{Fe}_{13}\right)$, accompanied by khatyrkite $\left(\mathrm{CuAl}_{2}\right)$ and cupalite (CuAl) in the $\mathrm{CV} 3$ carbonaceous chondrite Khatyrka has posed a mystery as to what extraterrestrial processes led to the formation and preservation of these metal alloys. Here we present a range of evidence, including the discovery of high-pressure phases never observed before in a CV3 chondrite, indicating that an impact shock generated a heterogeneous distribution of pressures and temperatures in which some portions reached at least $5 \mathrm{GPa}$ and $1,200^{\circ} \mathrm{C}$. The conditions were sufficient to melt $\mathrm{Al}-\mathrm{Cu}$-bearing minerals, which then rapidly solidified into icosahedrite and other $\mathrm{Al}-\mathrm{Cu}$ metal phases. The meteorite also contains heretofore unobserved phases of iron-nickel and iron sulphide with substantial amounts of $\mathrm{Al}$ and $\mathrm{Cu}$. The presence of these phases in Khatyrka provides further proof that the $\mathrm{Al}-\mathrm{Cu}$ alloys are natural products of unusual processes that occurred in the early solar system.

\footnotetext{
${ }^{1}$ Department of Geosciences, Princeton University, Guyot Hall, Princeton, New Jersey 08544, USA. ${ }^{2}$ Dipartimento di Scienze della Terra, Università di Firenze, Via La Pira 4, I-50121 Florence, Italy. ${ }^{3}$ Princeton Institute for the Science and Technology of Materials, Princeton University, Princeton, New Jersey 08544, USA. ${ }^{4}$ Division of Earth \& Atmospheric Sciences, Purdue University, West Lafayette, Indiana 47907, USA. ${ }^{5}$ Department of Mineral Sciences, National Museum of Natural History, Smithsonian Institution, Washington, District of Columbia 20013, USA. ${ }^{6}$ Department of Physics, Princeton University, Jadwin Hall, Princeton, New Jersey 08544, USA. ${ }^{7}$ Institute of Geology of Ore Deposits, Petrography, Mineralogy, and Geochemistry (IGEM), Russian Academy of Sciences, Staromonetny per. 35, Moscow 119017, Russia. ${ }^{8}$ Department of Earth, Atmospheric, and Planetary Sciences, Massachusetts Institute of Technology, Cambridge, Massachusetts 02139, USA. ${ }^{9}$ Geoscience Technology, BHP Billiton, Houston, Texas 77056, USA. ${ }^{10}$ Department of Earth and Planetary Sciences, Harvard University, 20 Oxford Street, Cambridge, Massachusetts 02138, USA. ${ }^{11}$ Division of Geological and Planetary Sciences, California Institute of Technology, Pasadena, California 91125, USA. ${ }^{12}$ Hitachi High Technologies America, Inc., Gaithersburg, Maryland 20878, USA. ${ }^{13}$ Princeton Center for Theoretical Science, Princeton University, Princeton, New Jersey 08544, USA. * These authors contributed equally to this work. $\dagger$ Present address: Advanced Material Characterization Laboratory, University of Delaware, Wilmington, North Carolina 19801, USA. Correspondence and requests for materials should be addressed to P.J.S. (email: steinh@princeton.edu).
} 
cosahedrite $\left(\mathrm{Al}_{63} \mathrm{Cu}_{24} \mathrm{Fe}_{13}\right)^{1,2}$, an alloy displaying a threedimensional icosahedral symmetry strictly forbidden for crystals $^{3,4}$, represents the first and, to date, the only known naturally occurring quasicrystal. It was discovered in the Khatyrka meteorite ${ }^{5-7}$, an oxidized subgroup (Allende-like) CV3 carbonaceous chondrite (CV3 CC) that formed at least 4.5 billion years ago. The preservation of a quasicrystal in a meteorite that formed at the early stages of the solar system indicates that it can be stable over cosmic time scales, giving new insights on the existence and stability of these materials in nature ${ }^{5,6}$. However, the processes that produced this unusual assemblage have been a mystery, as the highly reducing conditions implied by the presence of metallic $\mathrm{Al}$ are unknown for natural terrestrial materials and, before our studies, for meteorites. Moreover, the combination of metallic $\mathrm{Al}$ (high temperature refractory lithophile) with metallic $\mathrm{Cu}$ (low temperature chalcophile) is totally unexpected.

The results presented in this paper attempt to address these issues through a petrological investigation of sample no. 125 of the Khatyrka meteorite, a sample that provides clear evidence that the meteorite was subjected to a high-pressure impact shock, supplemented by studies of individual phases found in sample nos: 5, 121 and 126 (ref. 7). On the basis of the new data, our hypothesis is that the shock produced a heterogeneous distribution of high pressure and temperature, with localized melting of Al-Cu-bearing minerals followed by rapid cooling. We discuss two plausible scenarios for how the alloys initially formed that are consistent with the observations: shock-induced melting of $\mathrm{Al}-\mathrm{Cu}$-bearing iron-nickel and iron sulphide, or solar nebula origin followed later by shock melting and rapid cooling of $\mathrm{Al}-$ $\mathrm{Cu}$-bearing minerals.

\section{Results}

Description of samples. Sample no. 125 is part of the same CV3 CC as nos: 5 and 121 (ref. 7). The correlation is based on $\mathrm{O}$-isotope measurements of an olivine grain (Fig. 1), and the presence of the same types of minerals and rare $\mathrm{Cu}-\mathrm{Al}$ phases found in the other Khatyrka samples ${ }^{5-7}$. Also, the shocked portion of no. 125 has the appearance of a compressed (as from shock) CV3 matrix (Fig. 2b). Figure 3 shows a side-by-side comparison of the compressed matrix in no. 125 and uncompressed matrix in no. 121 (ref. 7). Because all of the grains in this meteorite are so small, we only have polished grain mounts and not thin sections. Thus, we cannot apply the usual shock estimates based on optical properties such as those introduced by Stöffler et al. ${ }^{8}$ and Scott et al. ${ }^{9}$ (for example, undulatory extinctions and planar fractures in olivine). Figure 3 clearly shows that the matrix of the unshocked grain no. 5 is very uncompacted (unlike, for example, Leoville, a reduced-subgroup CV3 with a highly compacted and lineated fabric). However, two of the grains of Khatyrka contain the highpressure phases ahrensite ${ }^{10}$ (Fe-rich ringwoodite) and stishovite, and it is from these that we derive the shock history of this meteorite. We note that shock effects in meteorites can be highly localized and difficult to identify; hence, we have focused on fragment no. 125 where shock is most evident and could be studied with minimal sample loss.

Evidence of shock pressures that exceeded $5 \mathrm{GPa}$. The silicates and oxides in sample no. 125 provide strong evidence of shock pressures that exceeded $5 \mathrm{GPa}$. In particular, we report here the presence of two high-pressure mineral phases: ahrensite, observed for the first time in a CV3 CC, and a new oxide spinelloid. The olivine grains of sample 125 are laced by a network of fine veins (Fig. 2c), each of which, under transmission electron microscopy (TEM) magnification, resembles a 'ladder' made up of alternating 'rungs' of ahrensite and of an amorphous $\mathrm{SiO}_{2}$-rich phase (Figs 4 and 5), similar to phases found in the Umbarger L6 chondrite ${ }^{11}$. Ahrensite can only form at pressures exceeding $5 \mathrm{GPa}$ (ref. 12). The ladders, the olivine hosts to the ladders and other silicates are cut by a network of fractures (Fig. 2b,c). These fractures, and interstices at triple junctions between olivine grains, are filled by nanometre-scale subhedral spinel crystals (bright in the scanning electron microscopy (SEM) backscattered electron images of Fig. 2b,c). Among these is a phase (Fig. 6a,c) with composition $\mathrm{Fe}_{3-x} \mathrm{Si}_{x} \mathrm{O}_{4}$ (with $x \approx 0.4$-TEM-energy dispersive spectrometry (TEM-EDS) data) and the orthorhombic structure reported for spinelloid $\mathrm{V}^{13}$. The occurrence of the spinelloid in this set of veins/fractures implies pressures of 3-8 GPa (ref. 13). See also Figs 7 and 8 for evidence of other new mineral phases (discussed below).

Evidence of temperatures reaching about $1,200{ }^{\circ} \mathrm{C}$. The ladder veins cutting the olivine provide evidence that portions of the sample reached a temperature of at least $1,200^{\circ} \mathrm{C}$. We plot the compositions of the $\mathrm{Si}-\mathrm{Fe}-\mathrm{Mg}$ phases in Fig. 9. Although most of the Fe-rich spinels in the spinel-filled veins plot at the Fe corner of Fig. 9, some contain silicon, including the spinelloid. On average, the composition of the other low $\mathrm{Ni}$ spinels in the fractures is $\left(\mathrm{Mg}_{0.94} \mathrm{Fe}_{0.78} \mathrm{Al}_{1.01} \mathrm{Ni}_{0.27}\right) \mathrm{O}_{4}$. Neglecting $\mathrm{Al}$ and $\mathrm{Ni}$, this composition projects onto the $\mathrm{Fe}-\mathrm{Mg}-\mathrm{Si}$ diagram in Fig. 9 at the inverted triangle.

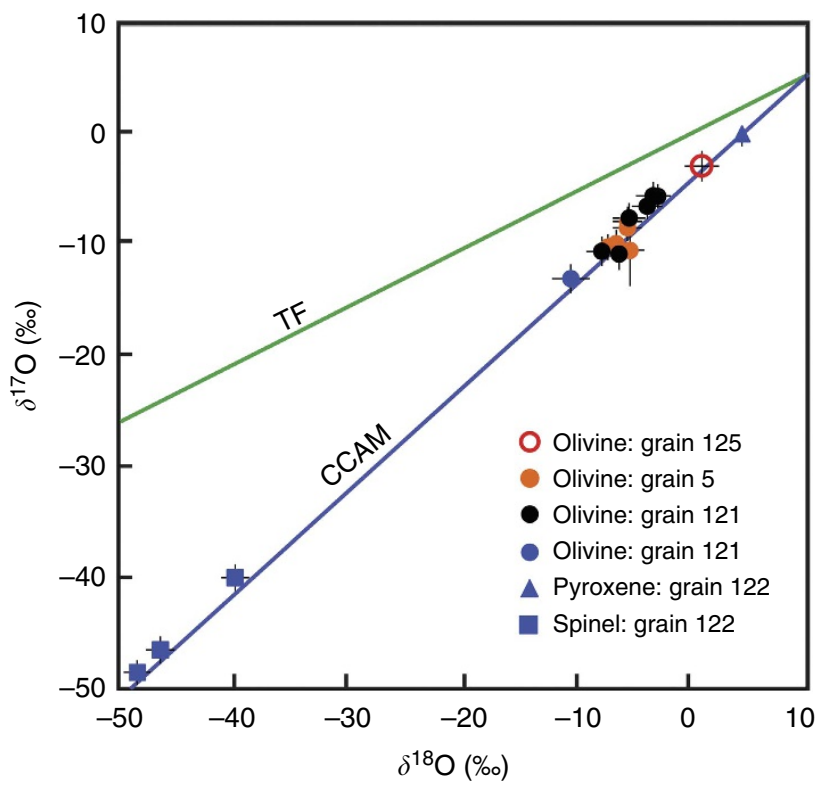

Figure 1 | Oxygen isotope composition. A plot of oxygen three-isotope composition $^{27}$ to discriminate terrestrial ( $\mathrm{TF}=$ terrestrial fractionation) and extraterrestrial (CCAM = carbonaceous chondrite anhydrous minerals) sources. The plot displays data for olivine from grain 125 (red open circle) with minerals from grains nos: 5 (orange solid symbols), 121 (black and blue solid symbols) and 122 (blue solid symbols) where the symbols correspond to pyroxene (triangles), olivine (circles) and spinel (squares) in the Khatyrka meteorite. All data are ion microprobe measurements made with the Cameca ims-7f geo. The error bars are $2 \sigma$. The plotted compositional indices, $\delta^{18} \mathrm{O}_{\text {VsMow }}$ and $\delta^{17} \mathrm{O}_{\text {VsMow }}$ (where VSMOW is Vienna Standard Mean Ocean Water), are the difference in ${ }^{18} \mathrm{O} /{ }^{16} \mathrm{O}$ and ${ }^{17} \mathrm{O} /{ }^{16} \mathrm{O}$ ratios, respectively, compared with the ratios in VSMOW, expressed in parts per thousand. Terrestrial minerals fall along the TF line (green line) with a slope of $\sim 0.5$; the oxygen isotope compositions measured for our samples lie along the line corresponding to anhydrous minerals in the CO or CV CC (blue line) with a slope of $\sim 1$. 


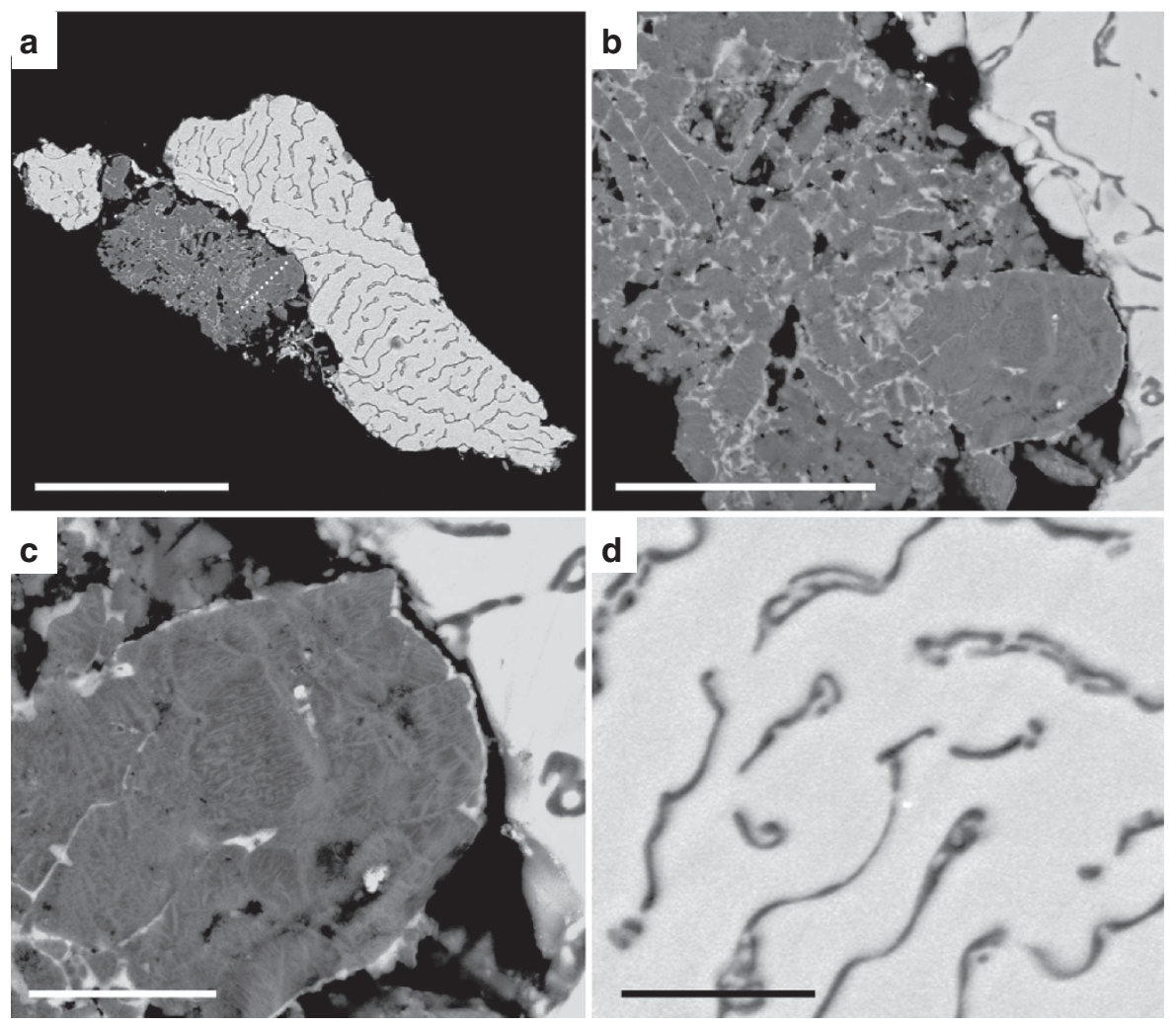

Figure 2 | SEM backscattered electron images of sample no. 125. (a) An overall view of the sample showing the oval-shaped aggregate of silicates and oxides bordered by an intergrowth of nearly pure metallic $\mathrm{Al}$ (thin grey wavy) in khatyrkite, $\mathrm{CuAl}_{2}$ (the brighter portions comprising most of the metallic grains); the two $\mathrm{CuAl}_{2}$ grains are in the same crystallographic orientation, based on electron backscattered diffraction (EBSD), and a re-polishing of the sample demonstrated that the two pieces are physically continuous; a FIB section was taken from the area indicated with the white dotted line; (b) close-up of the sample showing the fragmented nature of the silicate assemblage; (c) close-up of the silicate portion of the grain showing olivine with spinel-filled veins (thin light stripes) and the magnetite rim adjacent to the $\mathrm{CuAl}_{2}$ metal; (d) khatyrkite $\left(\mathrm{CuAl}_{2}\right)$ with wavy eutectic structure of nearly pure aluminium similar to that reported by Zimmerman et al. ${ }^{16}$ Scale bars, $50 \mu \mathrm{m}$ (a); and $5 \mu \mathrm{m}$ (b-d).
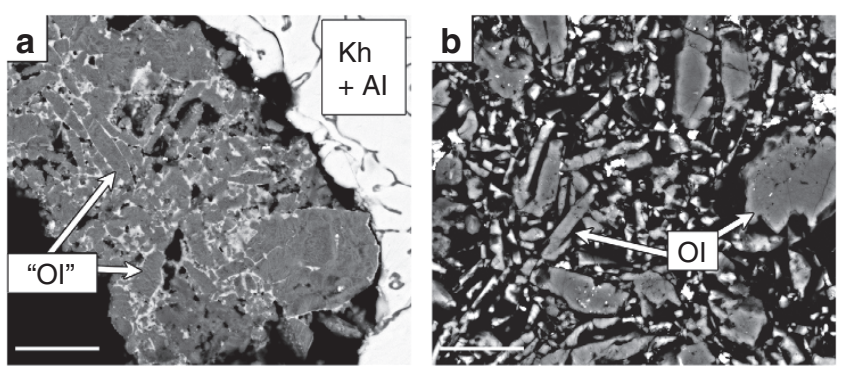

Figure 3 | Comparison of shocked and unshocked textures. Backscattered electron images of the shocked silicate textures in grain no. 125 (a) compared with the unshocked textures in Khatyrka matrix (b) from grain no. 5. Note that the 'olivine' grains in the left image have the same sizes and distinctive shapes as those in unshocked Khatyrka matrix, showing that the matrix was the precursor for the shocked silicates. Al, metallic aluminium; Kh, khatyrkite; Ol, olivine; 'Ol', shocked olivine grains, now consisting of ahrensite + forsterite + glass + spinels. Scale bars, $10 \mu \mathrm{m}$.

The cotectic and reaction paths on the liquidus in the $\mathrm{MgO}-$ $\mathrm{FeO}-\mathrm{SiO}_{2}$ system ${ }^{14}$ are shown by lines with arrows in Fig. 9; we here interpret our results in terms of the low-pressure olivine-silica cotectic (there are no high-pressure experimental data on this system), from the ternary peritectic (c, Fig. 9) at $1,305^{\circ} \mathrm{C}$ to the binary eutectic (d, Fig. 9) at $1,178^{\circ} \mathrm{C}$. The bulk composition of the ladders lies near the Fe-rich olivine-silica cotectic (c,d in Fig. 9), which is consistent with an interpretation that the ladders formed from a melt at about $1,200^{\circ} \mathrm{C}$. Following formation of the melts with the bulk composition of the ladders, the silica-rich phase and the ahrensite formed from a liquid with composition on the cotectic, with the compositions of the combined phases adding up to the bulk composition of the ladders.

The enrichment of $\mathrm{Si}$ in the ladders compared with the $\mathrm{Si}$ content of olivine and the much higher $\mathrm{Fe} / \mathrm{Mg}$ of the ladders than the host forsterite $\left(\mathrm{Fo}_{80-85}\right)$ imply an open system to produce a change in composition from forsterite to ahrensite $+\mathrm{SiO}_{2}$. The texture of the ladders between the 200-nm magnetite grain and forsterite (Figs 4a and 5) suggests that the ladders could have formed by a reaction between forsterite and magnetite, producing a melt with the bulk composition of the ladders; the $\mathrm{Mg}$ produced in this reaction may be in the spinels (inverted triangle in Fig. 9) that precipitated in the fractures. In Fig. 9, considering only the $\mathrm{Mg}, \mathrm{Fe}$ and $\mathrm{Si}$ components, a reaction is implied involving forsterite + magnetite as reactants and the ladders + spinel as products (see inset in Fig. 9).

Evidence of rapid cooling. The composition of the whole $\mathrm{Al}+\mathrm{CuAl}_{2}$ grain that partially encloses the silicate assemblage (Fig. 2a) is close to the peritectic (at about $600^{\circ} \mathrm{C}$ ) in the $\mathrm{Al}-\mathrm{Cu}$ system $\left(30 \% \mathrm{Cu}\right.$ and $\left.70 \% \mathrm{Al}^{15}\right)$, consistent with the metal solidifying late during the cooling. The grains exhibit a wavy eutectic structure (Fig. 2a,d) composed of nearly stoichiometric khatyrkite $\left(\mathrm{CuAl}_{2}\right.$, containing $\left.0.8 \% \mathrm{Fe}\right)$ and $\mathrm{Al}$ metal (containing $1 \% \mathrm{Cu}$ ). This texture is known to occur as a result of rapid cooling $\left(\sim 10^{2}-10^{3} \mathrm{Cs}^{-1}\right)$ of liquids in the $\mathrm{Al}-\mathrm{Cu}$ system $^{16-18}$. 

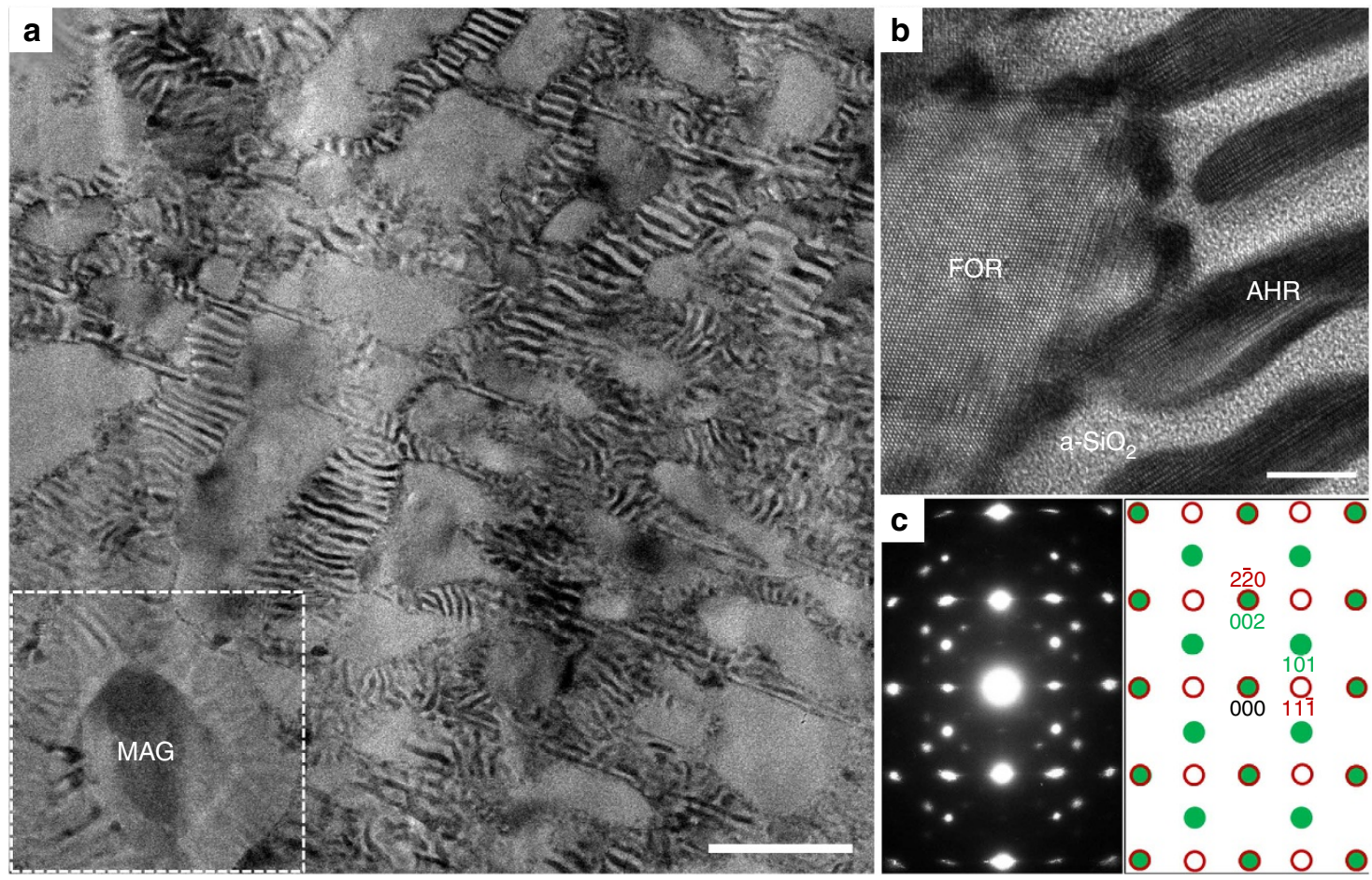

Figure 4 | Ladder-like veins. (a) TEM image from the FIB sample taken from a portion of the grain reported in Fig. 2a showing ladder-like veins (lamellar eutectic structure) of ahrensite (AHR) and an amorphous $\mathrm{SiO}_{2}$-rich phase (a-SiO 2 , Fig. 4b). In lower left part of the figure is an equant magnetite grain (MAG) surrounded by ladder veins (the white dotted box is shown enlarged in Fig. 5). (b) Close-up of ladder showing olivine (FOR) and ahrensite (AHR) regions whose electron diffraction patterns (along [010] and [112] zone axes, respectively) were obtained and superposed in c, showing that the two minerals exhibit a crystallographic alignment (green and empty circles refer to forsterite and ahrensite, respectively). Similar alignments were found throughout regions in a. Scale bars, $200 \mathrm{~nm}$ (a) and $5 \mathrm{~nm}$ (b).

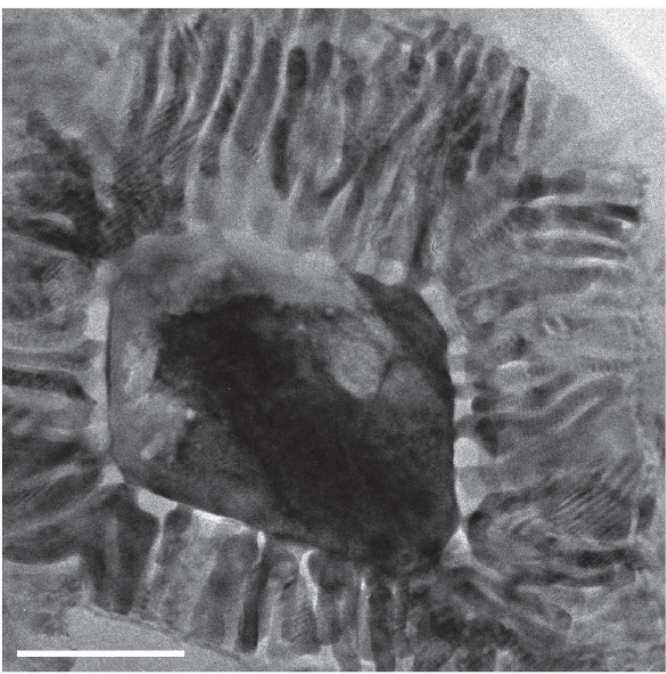

Figure 5 | Magnetite grain surrounded by ladder veins. The observed texture suggests that the ladders could have formed by a reaction between forsterite and magnetite, producing a melt with the bulk composition of the ladders. Scale bar, $100 \mathrm{~nm}$.

The lamellar eutectic texture of the ladder areas is also typical for a rapidly cooled composition beginning from a temperature near the olivine-silica cotectic in the $\mathrm{MgO}-\mathrm{FeO}-\mathrm{SiO}_{2}$ system (Fig. 9). Further evidence of rapid cooling is the presence of the amorphous high silica phase. The extreme difference in $\mathrm{Mg}$ number between the forsterite $\left(\mathrm{Fo}_{80}\right)$ and the average ladder $\left(\mathrm{Fo}_{20}\right)$ shows that the liquid was not in equilibrium with the host forsterite, despite the extremely small size of our samples. The absence of any reaction between the ladders and the host, considering the ease of diffusive equilibration of olivine, is a further indication of a very rapid cooling.

The $\mathrm{Cu}-\mathrm{Al}$ grain cuts across the trends of the spinel-filled fractures and veins (Fig. 2b,c) and of the ladders; therefore, it was the last portion of sample 125 to solidify. The thin rim of magnetite on the olivine adjacent to the $\mathrm{CuAl}_{2}$ composite grain (Fig. 2b) may be a vein wall, like the other thin spinel-filled veins. The lack of reaction between the highly reduced metallic Al-bearing metal of the metal nodule and the magnetite between the olivine and the $\mathrm{Cu}-\mathrm{Al}$ metal strongly suggests that the sample cooled too fast, and to too low of a temperature, for diffusion between the incompatible phases to occur.

Finally, evidence for rapid cooling can be observed by comparing the textures in the Khatyrka sample with those found in controlled laboratory rapid-cooling experiments ${ }^{19}$. (Although sample no. 125 does not include icosahedrite, here we consider the collection of phases observed in the various grains from Khatyrka.) In the ternary diagram for $\mathrm{Al}-\mathrm{Cu}-\mathrm{Fe}$, there is a small range of liquid compositions where icosahedrite is on the liquidus between 850 and $700{ }^{\circ} \mathrm{C}$ (see Figs 1 and 2 in Zhang and Lück ${ }^{20}$ ). This region is reached through a liquid line of descent from higher temperatures. During crystallization of icosahedrite from a liquid, a ternary peritectic with the phase omega $\left(\mathrm{Cu}_{2} \mathrm{FeAl}_{7}\right)$ is reached and the icosahedrite reacts out of the system. With further cooling, cupalite crystallizes together with omega along a cotectic until a ternary eutectic is reached where khatyrkite joins cupalite and omega. The composition of this residual liquid is very close to the composition of the binary peritectic with cupalite and khatyrkite; subsolidus phase diagrams for these compositions show that omega is the stable phase with khatyrkite and 


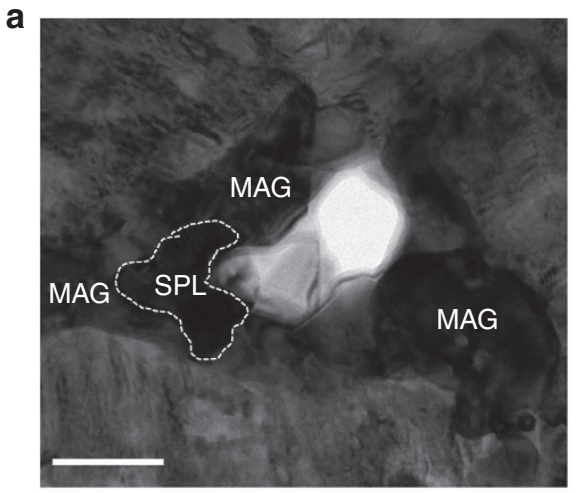

b
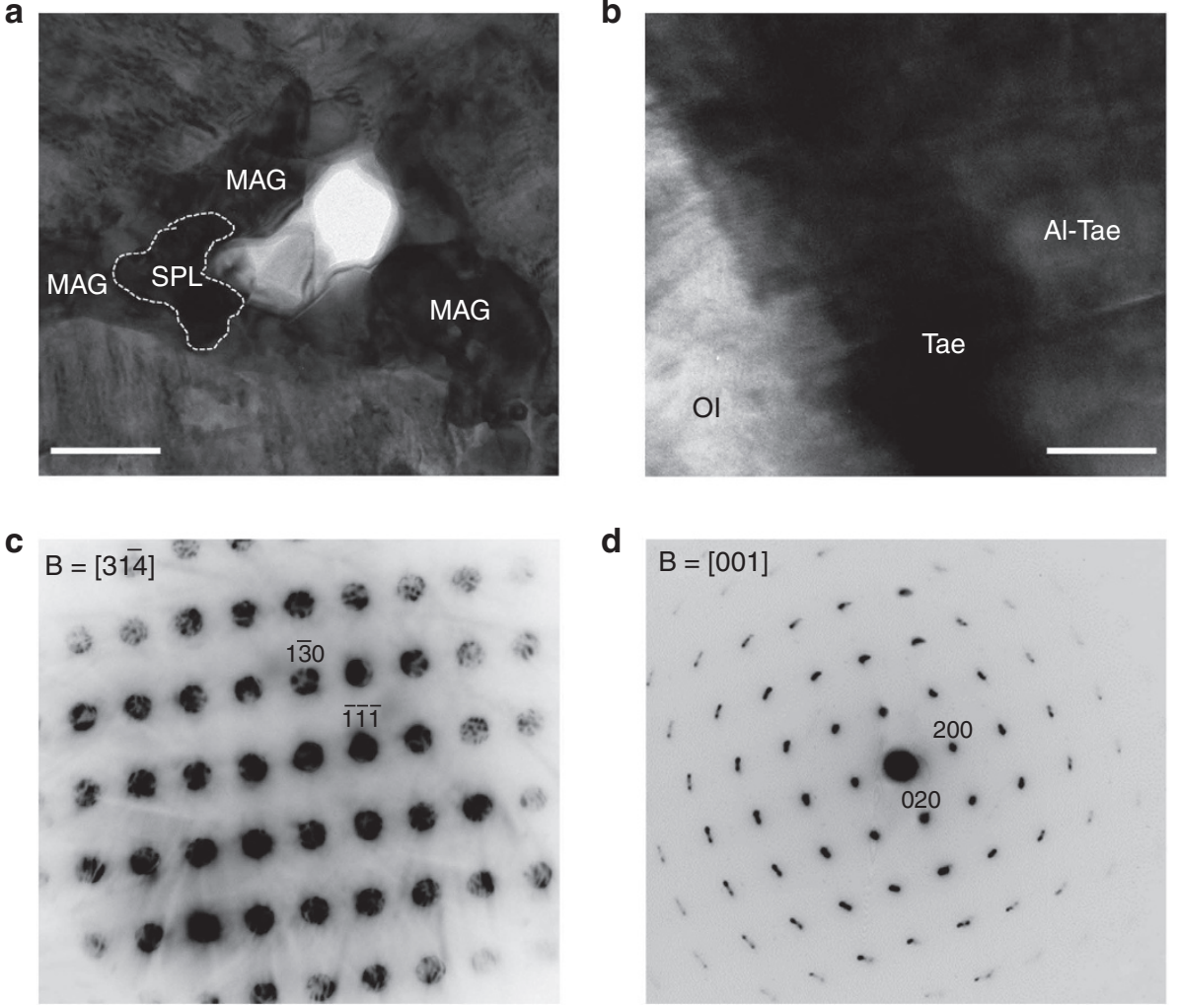

Figure 6 | TEM images of oxide and metallic phases. (a) Spinelloid $V(S P L)$ with composition $\mathrm{Fe}_{3-x} \mathrm{Si}_{x} \mathrm{O}_{4}$ (with $x \approx 0.4-\mathrm{TEM}$-EDS data) coexisting with magnetite (MAG) in fracture (bright white spot is a hole); scale bar, $200 \mathrm{~nm}$; (b) Al-Cu-bearing taenite (Al-Tae) associated with taenite (Tae) and olivine (OI); scale bar, $50 \mathrm{~nm}$. TEM-EDS data give $\mathrm{Fe}_{44} \mathrm{Ni}_{26} \mathrm{Al}_{18} \mathrm{Cu}_{12}, \mathrm{Fe}_{51} \mathrm{Ni}_{36} \mathrm{Cu}_{13}$ and $\left(\mathrm{Mg}_{1.95} \mathrm{Fe}_{0.05}\right) \mathrm{SiO}_{4}$; (c) convergent beam electron diffraction pattern along the [31 $\overline{4}]$ zone axis of the spinelloid $\mathrm{V}$ shown in $\mathbf{a}$; (d) electron diffraction pattern of $\mathrm{Al}$-Cu-bearing taenite shown in $\mathbf{b}$ down the [001] zone axis; the cubic cell parameter measured is $3.67( \pm 1) \AA$.
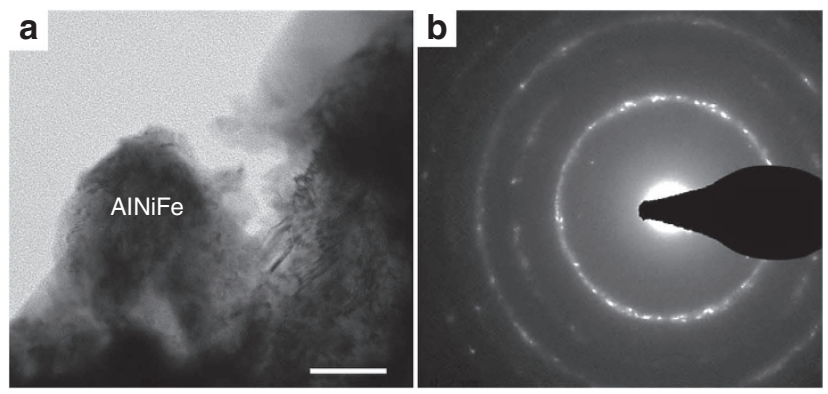

Figure 7 | A potential new mineral. (a) An unnamed AlNiFe phase with composition $\mathrm{Al}_{0.38} \mathrm{Ni}_{0.32} \mathrm{Fe}_{0.30}$ (WDS data), whose diffraction pattern (b) was indexed according to a bcc structure with $a=3.02( \pm 1) \AA$. Scale bar, $50 \mathrm{~nm}$.

cupalite $^{19,20}$. However, in Khatyrka, the samples do not have the phase omega. Zhang and Lück ${ }^{21}$ point out that omega does not appear in rapidly cooled liquid compositions where icosahedrite is on the liquidus; instead, those compositions end up with an assemblage of khatyrkite-cupalite-icosahedrite- $\beta$ (where $\beta$ is $\mathrm{AlCuFe}$ solid solution); this assemblage is observed in Khatyrka, with icosahedrite and $\beta$ remaining as unreacted phases in an assemblage containing cupalite and khatyrkite (see Fig. 2 in Bindi et al. $\left.^{1}\right)$.

Al- and Cu-bearing FeNi metals. The presence of Al- and $\mathrm{Cu}$ bearing FeNi metals is a strong evidence that FeNi and the $\mathrm{Al}-$ Cu-bearing metals coexisted during the impact shock. A critical
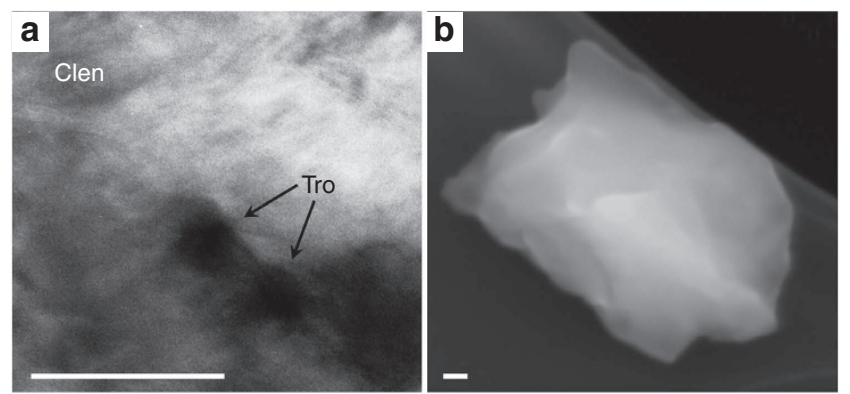

Figure 8 | Al- and $\mathbf{C u}$-bearing sulphides. (a) Cu-bearing troilite (Tro) with composition $\left(\mathrm{Fe}_{0.47} \mathrm{Ni}_{0.28} \mathrm{Cu}_{0.25}\right.$ )S (TEM-EDS data) associated with clinoenstatite (Clen) with composition $\left(\mathrm{Mg}_{1.80} \mathrm{Fe}_{0.20}\right) \mathrm{Si}_{2} \mathrm{O}_{6}$ (TEM-EDS data); (b) Al-bearing iron sulphide with composition $\left(\mathrm{Fe}_{0.84} \mathrm{Al}_{0.04}\right) \mathrm{S}_{1.12}$ (SEM-EDS data). Scale bar, $50 \mathrm{~nm}$.

finding is the discovery of two new minerals, Al-Cu-bearing taenite (Al-Tae) associated with taenite (Tae) and olivine (Ol) (Fig. 6b,d) and an unnamed AlNiFe phase with composition $\mathrm{Al}_{0.38} \mathrm{Ni}_{0.32} \mathrm{Fe}_{0.30}$ (Fig. 7). In addition, we have found a $\mathrm{Cu}$ bearing troilite (Fig. 8a) and an Al-bearing iron sulphide (Fig. 8b). The cubic cell parameter measured for taenite is $3.67( \pm 1) \AA$, slightly larger than that reported for pure taenite 22 (that is, $3.58 \AA$ ), in agreement with the incorporation of the larger $\mathrm{Al}$ ion $^{23}$ in the structure. The diffraction pattern of $\mathrm{Al}_{0.38} \mathrm{Ni}_{0.32} \mathrm{Fe}_{0.30}$ was indexed according to a bcc structure with $a=3.02( \pm 1) \AA$, which corresponds to the A2 structure in the Al-Ni-Fe system ${ }^{24}$. 


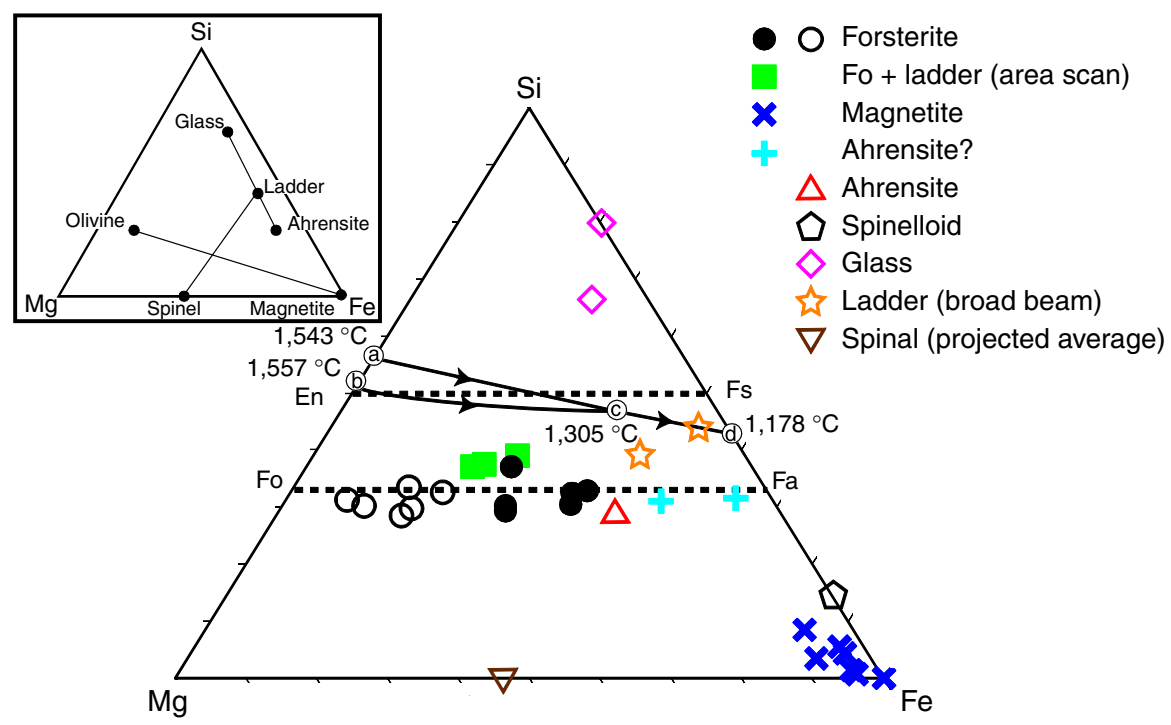

Figure 9 | Compositions of phases plotted in terms of normalized Si-Fe-Mg. Results (in atomic \%) are based on SEM-EDS (closed symbols) and TEMEDS (open symbols) measurements. Projections of the cotectic and reaction paths on the low pressure liquidus for the system $\mathrm{MgO}^{-} \mathrm{FeO}-\mathrm{SiO}{ }_{2}$ (ref. 14 ) are shown by lines with arrows. Between 1,543 and $1,305^{\circ} \mathrm{C}$ is the silica-pyroxene cotectic (a-c); between 1,557 and $1,305^{\circ} \mathrm{C}$ is the pyroxene-olivine reaction path (b-c); and between 1,305 and $1,178^{\circ} \mathrm{C}$ is the silica-olivine cotectic (c-d). Along the forsterite (Fo)-fayalite (Fa) join, the analyses range from Fo 89 (TEM) to $\mathrm{Fo}_{11}$ (SEM). (En, enstatite; Fs, ferrosilite). The bulk compositions of the ladders (obtained by broad beam TEM-EDS) are shown as open stars. They lie off the Fo-Fa join towards Si, and are close to the olivine-silica cotectic. Averaged TEM-EDS analyses (obtained using a beam size of $2 \mathrm{~nm}$ ) are shown as open diamonds for the silica rungs of the ladders, and as open triangle for the ahrensite rungs. The SEM-EDS analyses plotted as plus signs may also be ahrensite in that they are more Fe rich than the identified ahrensite. The three filled squares are analyses from SEM-EDS scans over relatively large areas of olivine grains. These include the Fe-rich veins referred to as ladders. These analyses lie between the TEM-EDS forsterite analyses (open circles) and the TEM-EDS broad beam ladder analyses (open stars). This is consistent with the compositions determined by the SEM X-ray area scans to lie along a mixing line between the ladder compositions and forsterite. The SEM-EDS area scans show the relative enrichment of Si in the composite grain due to the presence of the silica phase in the ladders. The inset illustrates reactions discussed in the text: the crossing tie lines show the reaction olivine + magnetite $=$ ladder + spinel. Because the spinel also contains $\mathrm{Ni}$ and $\mathrm{Al}$, the reactants must include phases with $\mathrm{Ni}$ and $\mathrm{Al}$ (or a phase that contains both, such as shown in Figs $6 \mathrm{~b}$ and $7 \mathrm{a}$ ). Also shown are silica and ahrensite that formed from rapidly cooled liquid with the composition of the ladders (open stars).

The presence of khatyrkite, cupalite and icosahedrite with the Al$\mathrm{Cu}$-bearing taenite in the $\mathrm{CV} 3 \mathrm{CC}$ suggests that $\mathrm{Al}-$ and $\mathrm{Cu}$ bearing FeNi metals were transported during the shock event without any significant oxidation reaction, which is plausible if the shock event occurred in contact with the highly reducing solar nebula gas.

Studies by Rubin ${ }^{25}$ identified examples of ordinary chondrites containing $\mathrm{Cu}$-bearing $\mathrm{FeNi}$ grains that underwent impacts and suggested that the impacts led to shock-generated melting and the extraction of the $\mathrm{Cu}$ into metallic droplets. Now we have observed in Khatyrka that $\mathrm{FeNi}$ can host $\mathrm{Al}$ and $\mathrm{Cu}$, both separately and together. The $\mathrm{Al}$ - and $\mathrm{Cu}$-bearing $\mathrm{FeNi}$ phases might have been the initial source of the $\mathrm{CuAl}$ metals (khatyrkite, cupalite and icosahedrite), thus explaining how the lithophilic $\mathrm{Al}$ and chalcophylic $\mathrm{Cu}$ became associated. Alternatively, the $\mathrm{Al}-\mathrm{Cu}$ metals may have had a pre-accretion nebular origin and the Aland $\mathrm{Cu}$-bearing taenite observed in the sample formed by shockinduced reaction of the $\mathrm{Cu}-\mathrm{Al}$ melt and taenite. We discuss both possibilities below.

\section{Discussion}

One hypothesis for explaining the properties of Khatyrka described above is that the shock we have documented locally generated the heat and pressure necessary to extract $\mathrm{Al}$ and $\mathrm{Cu}$ from the FeNi metals and to initiate the local melting of metals and silicate; the $\mathrm{Al}$ and $\mathrm{Cu}$ would then be dissolved in a silicate melt from which the $\mathrm{Al}-\mathrm{Cu}-\mathrm{Fe}$ alloys precipitated, along with forsterite and diopside (see Fig. 1 in Bindi et al. ${ }^{5}$ ). The local, transient ultra-high pressures led to the nucleation and growth of ahrensite and spinelloid V. Icosahedrite could have grown from melted metals, and stishovite could have grown around it while the pressure was still high, thus explaining the stishovite grains with icosahedrite inclusions found in the original museum sample 5 .

The alternate hypothesis is that the $\mathrm{Cu}-\mathrm{Al}$ metals formed in some nebular process before the impact that formed the silicate ladders and that the impact resulted in the remelting, rapid cooling and solidification of the $\mathrm{CuAl}$ metals. This hypothesis has the advantages that it can naturally account for the icosahedrite inclusions in stishovite and that it can explain why $\mathrm{CuAl}$ metal grains are found in some other Khatyrka samples-for example, grain nos: 5 and 121-that show no evidence of shock ${ }^{7}$. In either model, the sequence of events that formed Khatyrka's metal must have occurred in contact with the reducing solar nebula gas. If the magnetite present in our sample is indicative of oxidizing conditions during the shock event, then that process must have been so rapid that there was no equilibration of oxygen with the metals.

The properties described above cannot plausibly be explained as being due to terrestrial atmospheric entry and impact. Atmospheric entry is far too oxidizing and the pressure does not reach the values indicated by ahrensite and spinelloid V. The formation of ahrensite and stishovite requires very high pressures, not just high temperatures, which could only occur in hypervelocity impacts that would leave sizeable craters. On the basis of the sediments hosting the grains, the impact likely occurred $<10 \mathrm{Ka}$ (ref. 7), and no evidence of a significant crater formed since has been found in our studies of the region. 
By contrast, taking into account the presence of $\mathrm{Cu}$ in moderating the fugacity requirements to form metallic $\mathrm{Al}$, the reducing conditions needed to make the metal are consistent with those inferred to exist in the presolar nebula at $4.5 \mathrm{Ga}$ (ref. 26). According to our first hypothesis, the $\mathrm{Cu}$ and $\mathrm{Al}$ are extracted from the FeNi lattice as a result of the impact; according to the second, $\mathrm{CuAl}$ metals already existed before impact and the $\mathrm{Cu}$ and $\mathrm{Al}$ subsequently entered the FeNi. Either way, this exchange of metallic $\mathrm{Al}$ and $\mathrm{Cu}$ can only be plausibly imagined to occur in space under solar nebular conditions, and not during terrestrial entry and impact.

Both hypotheses leave open the very challenging question of how the metallic $\mathrm{Al}$ - and $\mathrm{Cu}$-bearing phases, whether $\mathrm{AlCu}$ bearing $\mathrm{FeNi}$ for the first hypothesis or AlCu alloy for the second hypothesis, formed in the first place given that $\mathrm{Al}$ and $\mathrm{Cu}$ have two profoundly different cosmochemical properties and normally condense under very different conditions. What we have established is that, in either explanation, impact shock in space that occurred billions of years ago played a key role in the formation of icosahedrite and other $\mathrm{Al}-\mathrm{Cu}$-bearing alloys, as well as the combination of other unusual phases observed in Khatyrka, including several phases never seen before in a CV3 CC and some never seen before in any natural material. Experiments are now underway to study the stability of icosahedrite at high pressures and temperatures, and to recreate in the laboratory the highpressure shock-melting conditions that could have triggered the extraction of $\mathrm{Al}$ and $\mathrm{Cu}$ from $\mathrm{FeNi}$ phases. These studies may enable us to test and distinguish our hypotheses.

\section{Methods}

Sample characterization techniques. The samples studied here (nos: 125 and 126 recovered from the expedition in the Koryak Mts. ${ }^{6,7}$ ) were investigated by means of EDS, SEM, focused ion beam (FIB), WDS (wavelength dispersive spectrometry) and TEM techniques. An olivine fragment from sample 125 was selected for the SIMS (secondary ion mass spectrometry) O-isotope studies.

Scanning electron microscopy. Grains nos: 125 and 126 were first investigated with a SEM. The instrument used was a FEI Quanta 200 FEG Environmental-SEM equipped with an Oxford INCA Synergy 450 energy-dispersive X-ray microanalysis system, operated at 15 and $5 \mathrm{kV}$ accelerating voltage, $140 \mathrm{pA}$ probe current, 2,000 c.p.s. as average count rate on the whole spectrum and a counting time of $60 \mathrm{~s}$. Samples were sputter coated with a 5-nm-thick carbon film. The lower voltages were used to minimize secondary radiation from adjacent phases. Standards for the metals and olivine were forsterite $(\mathrm{Mg}, \mathrm{Si})$ and synthetic icosahedrite $(\mathrm{Al}, \mathrm{Cu}, \mathrm{Fe})$.

Electron microprobe. We carried out WDS electron microprobe analyses on an AlNiFe grain (about $5 \mu \mathrm{m}$ in size, larger than the one in Fig. $7 \mathrm{a}$ and showing an almost tabular morphology) using a JEOL JXA-8600 electron microprobe operating at an accelerating voltage of $15 \mathrm{kV}$, beam current of $20 \mathrm{nA}$ and a beam diameter of $1 \mu \mathrm{m}$. Variable counting times were used: $30 \mathrm{~s}$ for $\mathrm{Al}, \mathrm{Ni}$ and $\mathrm{Fe}$, and $60 \mathrm{~s}$ for the minor elements $\mathrm{Mg}, \mathrm{Si}, \mathrm{Cr}, \mathrm{P}, \mathrm{Co}, \mathrm{Cu}, \mathrm{Cl}, \mathrm{Ca}, \mathrm{Zn}$ and $\mathrm{S}$. Replicate analyses of synthetic $\mathrm{Al}_{53} \mathrm{Ni}_{42} \mathrm{Fe}_{5}$ were used to check accuracy and precision. The crystal fragment was found to be homogeneous within analytical error. The standards used were: metal-Al $(\mathrm{Al})$, synthetic $\mathrm{Ni}_{3} \mathrm{P}(\mathrm{Ni}, \mathrm{P})$, synthetic $\mathrm{FeS}(\mathrm{Fe})$, metal-Mg $(\mathrm{Mg})$, metal-Si $(\mathrm{Si})$, metal-Cr $(\mathrm{Cr})$, metal-Co $(\mathrm{Co})$, metal-Cu $(\mathrm{Cu})$, synthetic $\mathrm{CaCl}_{2}(\mathrm{Ca}$, $\mathrm{Cl})$ and synthetic $\mathrm{ZnS}(\mathrm{Zn}, \mathrm{S})$

FIB and TEM. In preparation for the study with TEM, a thin lamella cross-section from sample no. 125 was collected using the FIB technique. The sample was prepared using a standard process for deep trench milling and lift out in the FIB/ SEM Hitachi NB5000. Final milling was performed using a fine $5 \mathrm{kV} \mathrm{Ga}^{+}$beam of $120 \mathrm{nA}$ for cleaning and amorphous removal from the front and back side of the lamella. The thickness of the final lamella is $<80 \mathrm{~nm}$. The subsequent TEM study was done using a Philips CM200-FEG TEM (operating at $200 \mathrm{KeV}$ ) operated using the standard high-resolution imaging and micro/nano diffraction mode. Another JEOL JEM 2010 (operating at $200 \mathrm{kV}$ with an ultra-high resolution pole piece, and a point-to-point resolution close to $1.9 \AA$ ) was also used.

The FIB section was studied only using the Philips CM200-FEG TEM, whereas a powder from sample no. 126 was studied using both TEMs. The powder from sample no. 126 was placed on an Au mesh TEM grid ( 300 mesh, $3 \mathrm{~mm}$ in diameter) that was previously covered by a thin carbon layer (support film). EDS data were obtained using Evex NanoAnalysis System IV attached to the Philips CM200-FEG
TEM. A small electron probe of $20-100 \mathrm{~nm}$ was used with a count rate of $100-300$ c.p.s. using an average collection time of $180 \mathrm{~s}$. The quantitative analyses were done at $200 \mathrm{kV}$ and are based on using pure elements and the NIST 2063a standard sample as a reference under the identical TEM operating conditions.

Secondary ion mass spectrometry. Oxygen isotopic compositions, to discriminate terrestrial and extra-terrestrial minerals ${ }^{27}$, of a large olivine grain were obtained using the Cameca ims-7f geo ion microprobe (Fig. 1). The measurements were made with a relatively large $(\sim 15 \mu \mathrm{m})$, intense $(0.2 \mathrm{nA})$ primary ion beam and resulted in relatively precise measurements $\left(\sim \pm 2-2.5 \%\right.$ for both ${ }^{17} \mathrm{O}$ and $\left.{ }^{18} \mathrm{O}, 2 \sigma\right)$ of the isotopic compositions in a large olivine grain. Standards used for this analysis are San Carlos olivine, Eagle Station olivine and Burma spinel Secondary ions were collected by peak jumping into either a Faraday cup $\left({ }^{16} \mathrm{O}^{-}\right)$ or electron multiplier $\left({ }^{17} \mathrm{O}^{-}\right.$and $\left.{ }^{18} \mathrm{O}^{-}\right)$at a mass resolving power of $\sim 6,500$, easily resolving the ${ }^{16} \mathrm{OH}^{-}$interference on ${ }^{17} \mathrm{O}^{-}$.

\section{References}

1. Bindi, L., Steinhardt, P. J., Yao, N. \& Lu, P. J. Natural quasicrystals. Science 324 1306-1309 (2009).

2. Bindi, L., Steinhardt, P. J., Yao, N. \& Lu, P. J. Icosahedrite, $\mathrm{Al}_{63} \mathrm{Cu}_{24} \mathrm{Fe}_{13}$, the first natural quasicrystal. Am. Mineral. 96, 928-931 (2011).

3. Levine, D. \& Steinhardt, P. J. Quasicrystals: a new class of ordered structures Phys. Rev. Lett. 53, 2477-2480 (1984).

4. Shechtman, D., Blech, I., Gratias, D. \& Cahn, J. Metallic phase with long-range orientational order and no translational symmetry. Phys. Rev. Lett. 53, 1951-1953 (1984).

5. Bindi, L. et al. Evidence for the extra-terrestrial origin of a natural quasicrystal Proc. Natl Acad. Sci. USA 109, 1396-1401 (2012).

6. Steinhardt, P. J. \& Bindi, L. In search of natural quasicrystals. Rep. Prog. Phys 75, 092601-092611 (2012)

7. MacPherson, G. J. et al. Khatyrka, a new CV3 find from the Koryak Mountains Eastern Russia. Met. Planet. Sci. 48, 1499-1514 (2013).

8. Stöffler, D., Keil, K. \& Scott, E. R. D. Shock metamorphism of ordinary chondrites. Geochim. Cosmochim. Acta 55, 3845-3867 (1991).

9. Scott, E. R. D., Keil, K. \& Stöffler, D. Shock metamorphism of carbonaceous chondrites. Geochim. Cosmochim. Acta 56, 4281-4293 (1992).

10. Ma, C. et al. Discovery of ahrensite, $\gamma-\mathrm{Fe}_{2} \mathrm{SiO}_{4}$ and tissintite (Ca,Na,[]) $\mathrm{AlSi}_{2} \mathrm{O}_{6}$ : two new high pressure minerals from the Tissint Martian meteorite. 45th Lunar Planetary Science Conference. Abstract \#1222 (The Woodlands, Texas, USA 2014).

11. Xie, Z., Tomioka, N. \& Sharp, T. G. Natural occurrence of $\mathrm{Fe}_{2} \mathrm{SiO}_{4}$-spinel in the shocked Umbarger L6 chondrite. Am. Mineral. 87, 1257-1260 (2002).

12. Stixrude, L. \& Lithgow-Bertelloni, C. Thermodynamics of mantle minerals. Geophys. J. Int. 184, 1180-1213 (2011).

13. Ohtaka, O., Tobe, H. \& Yamanaka, T. Phase equilibria for the $\mathrm{Fe}_{2} \mathrm{SiO}_{4}-\mathrm{Fe}_{3} \mathrm{O}_{4}$ system under high pressure. Phys. Chem. Min. 24, 555-560 (1997).

14. Bowen, N. L. \& Schairer, J. F. The system $\mathrm{MgO}-\mathrm{FeO}-\mathrm{SiO}_{2}$. Am. J. Sci. 29, 151-217 (1935)

15. Murray, J. L. The aluminium-copper system. Int. Met. Rev. 30, 211-234 (1985).

16. Zimmerman, M., Carrard, M. \& Kurz, W. Rapid solidification of Al-Cu eutectic alloy by laser remelting. Acta Metal. 37, 3305-3313 (1989).

17. Lee, S. M. et al. Solidification sequence of the icosahedral quasicrystal forming Al-Cu-Fe alloys. Mater. Sci. Eng. A 304-306, 871-878 (2001).

18. Srivastava, R. M. et al. Cooling rate evaluation for bulk amorphous alloys from eutectic microstructures in casting processes. Metal. Trans. 43, 1670-1675 (2002).

19. Bancel, P. A. in Quasicrystals: the State of the Art (eds DiVincenzo, D. \& Steinhardt, P. J.) 17-56 (World Scientific, 1991).

20. Zhang, L. \& Lück, R. Phase diagram of the Al-Cu-Fe quasicrystal-forming alloy system. I. Liquidus surface and phase equilibria with liquid. Z. Metallkd. 94, 91-97 (2003)

21. Zhang, L. \& Lück, R. Phase diagram of the Al-Cu-Fe quasicrystal-forming alloy system. V. Solidification behaviour of Al-Cu-Fe quasicrystal forming alloys. Z. Metallkd. 94, 774-781 (2003).

22. Ramsden, A. R. \& Cameron, E. N. Kamacite and taenite superstructures and a metastable tetragonal phase in iron meteorites. Am. Mineral. 51, 37-55 (1966)

23. Kaye, G. W. C. \& Laby, T. H. Tables of Physical and Chemical Constants 15 edn (Longman, 1993).

24. Zhang, L. \& Du, Y. Thermodynamic description of the Al-Fe-Ni system over the whole composition and temperature ranges: modeling coupled with key experiment. Calphad 31, 529-540 (2007).

25. Rubin, A. E. Metallic copper in ordinary chondrites. Met. Planet. Sci. 29, 93-98 (1994).

26. Grossman, L. et al. Redox conditions in the solar nebula: observational, experimental and theoretical constraints. Rev. Mineral. Geochem. 68, 93-140 (2008).

27. Clayton, R. N., Onuma, N. \& Mayeda, T. K. A classification of meteorites based on oxygen isotopes. Earth Planet. Sci. Lett. 30, 10-18 (1976). 


\section{Acknowledgements}

L.B. thanks M.I.U.R., P.R.I.N. 2009 project 'Structure, microstructure and properties of minerals', the 'MEMA', Centro di Microscopia Elettronica e Microanalisi, Florence, Italy, and 'CRIST', Centro di Cristallografia Strutturale, Sesto Fiorentino, Florence, Italy. This work was supported in part by the National Science Foundation-MRSEC program through New York University (DMR-0820341; P.J.S.), through the Princeton Center for Complex Materials (DMR-0819860; N.Y.) and NASA grant NNX11AD43G (G.J.M.).

The expedition to Chukotka was supported by a grant from an anonymous donor to Princeton University (P.J.S., Principal Investigator).

\section{Author contributions}

The study was conceived and guided by L.S.H., L.B., C.L.A., G.J.M. and P.J.S., who also led the research team. L.S.H., L.B., N.Y., G.R.P., G.J.M. and C.L. performed the SEM studies. L.S.H., L.B., N.Y., C.L., J.J.C. and P.J.S. performed the FIB-TEM studies. J.M.E. and Y.G. carried out the oxygen isotope measurements. L.B., C.L.A., G.J.M., V.V.D., M.P.E., A.K., V.K., W.M.S., M.Y. and P.J.S. participated in the scientific expedition to Chukotka in 2011 and helped to recover the new samples. L.S.H., L.B., G.J.M. and P.J.S wrote the paper. All the authors discussed the results and commented on the manuscript.

\section{Additional information}

Competing financial interests: The authors declare no competing financial interests.

Reprints and permission information is available online at http://npg.nature.com/ reprintsandpermissions/

How to cite this article: Hollister, L. S. et al. Impact-induced shock and the formation of natural quasicrystals in the early solar system. Nat. Commun. 5:4040 doi: $10.1038 /$ ncomms5040 (2014). 